\title{
economia
}

ensaios

\section{Transição Demográfica e o Regime Geral da Previdência Social no Brasil}

Demographic Transition and the General Social Security System in Brazil

\section{Cleiton Silva de Jesus ${ }^{\mathrm{a}}$}

Resumo: A população brasileira está envelhecendo rapidamente, e a maior parte da despesa primária no país é aquela destinada à previdência e à assistência social. Os dados fiscais revelam que a fatia da despesa previdenciária na despesa primária total cresceu ao longo das últimas décadas, e não há perspectivas de reversão dessa tendência no médio prazo se as regras previdenciárias vigentes não forem alteradas. Nesse sentido, o objetivo deste artigo é mostrar os grandes números das projeções populacionais no Brasil e estimar uma função de reação fiscal adaptada aos dados previdenciários. A base de dados utilizada nos exercícios econométricos possui periodicidade trimestral e cobre o período de 1998-2018. Os principais resultados desses exercícios sugerem que o déficit do Regime Geral da Previdência Social (RGPS) é financeiramente insustentável, uma vez que está positivamente associado à dívida previdenciária do período anterior. Se esses resultados estiverem corretos, as regras vigentes do sistema de previdência e assistência social no Brasil devem ser urgentemente modificadas.

Palavras-chave: Previdência Social; Sustentabilidade; Função de Reação Fiscal. Classificação JEL: $\mathrm{H}_{55}$, $\mathrm{H}_{3}$

\begin{abstract}
The Brazilian population is rapidly aging and currently most of the country's primary expenditure is directed to the public pension system. The pension expenditures in relation to the total primary expenditure has grown over the last decades, and without changes in the current social security rules, there is no sign of change to this trend. This article aims to estimate a fiscal reaction adapted to the social security data and to present an overview of the population dynamics in Brazil. We used quarterly data from 1998 to 2018 to estimate the econometric model. The main results obtained in our estimates suggest that the General Social Security System (RGPS) deficit has an explosive trajectory since the current pension deficit is statistically associated with the lagged value of the pension debt. If our results are correct, the rules of the social security system in Brazil should be urgently changed.
\end{abstract}

Keywords: Social Security; Sustainability; Fiscal Reaction Function.

a Professor Adjunto na Universidade Estadual de Feira de Santana. E-mail: csj@uefs.br. 


\section{Introdução}

A sustentabilidade do Regime Geral da Previdência Social (RGPS) no Brasil é um tema que tem gerado intenso debate dentro e fora da academia. Por um lado, há os que argumentam que a sociedade brasileira não conseguirá sustentar as despesas com a previdência social nas próximas décadas dado o distanciamento entre a estrutura do RGPS e os regimes previdenciários de outras nações, além do rápido envelhecimento populacional (GIAMBIAGI, 2007; TAFNER, 2012; BANCO MUNDIAL, 2017; COSTANZI et al, 2018). Por outro lado, há os que negam a existência do déficit previdenciário e resistem em aceitar propostas de reformas constitucionais no sistema previdenciário que alinhem o sistema brasileiro com o de outros países do mundo (GENTIL, 2007; PAIM, MOTA e JOSÉ, 2017).

De acordo com a Constituição Federal de 1988, o sistema de seguridade social é composto pelas áreas de saúde, assistência social e previdência, e estabelece que o piso previdenciário deve ser o salário mínimo vigente. Essa Constituição, por um lado, reza que a previdência social (foco desta pesquisa) deve ser de caráter contributivo, de filiação obrigatória e que devem ser observados critérios que preservem o equilíbrio financeiro e atuarial, ao passo que a assistência social, por outro lado, deverá ser prestada a quem dela necessitar, independentemente de contribuição prévia do beneficiário ao sistema de seguridade social. A previdência social no Brasil, além de explicitar o caráter solidário entre as diferentes gerações uma vez que os mais jovens de hoje contribuem para os mais velhos de hoje -, também pode ser vista como uma política pública que prioriza os grupos menos favorecidos em detrimento dos grupos mais favorecidos no mercado de trabalho. A aposentadoria rural e as regras para a concessão de benefícios previdenciários para as mulheres são dois notáveis exemplos. Desde a unificação dos sistemas previdenciários urbano e rural, em 1988, já se sabia que as contribuições rurais não seriam suficientes para arcar com os benefícios dos trabalhadores rurais ao longo do tempo. No que tange à questão de gênero, argumenta-se que as mulheres devem receber um bônus na regra de concessão de aposentadorias devido ao fato de exercerem uma jornada de trabalho dupla (sobreposição entre trabalho remunerado e não remunerado) durante os anos de atividade.

É importante ressaltar que o nível de pobreza da população idosa no Brasil é baixo para os padrões internacionais, e que a taxa de pobreza seria muito alta para esse grupo da população ${ }^{1}$ se não houvesse um amplo conjunto de transferências públicas, incluindo os benefícios de aposentadorias contributivos e não contributivos estabelecidos pela Constituição de 1988 (BIRD, 2011). A despeito dessa

\footnotetext{
${ }^{1}$ No entanto, como explicitado em BIRD (2011, p. 42), “o mesmo não pode ser dito a respeito da pobreza entre as crianças".
} 
ponderação, sabe-se que o estudo da questão previdenciária (entendida como um seguro social) deve levar em conta, além da legislação vigente e da função distributiva do Estado, a dinâmica demográfica e a situação corrente das finanças públicas $^{2}$. A análise rigorosa dessa questão, devidamente abalizada nos dados disponíveis e na literatura acadêmica especializada, permite-nos fazer inferências sobre a sustentabilidade da legislação previdenciária vigente.

As projeções populacionais do Instituto Brasileiro de Geografia e Estatística (IBGE) revisadas em 2018 sugerem que a população brasileira envelhecerá muito rápido, e mostram que, já a partir do biênio 2018-2019, a taxa de crescimento da população total deverá superar a taxa de crescimento da população em idade ativa. O fenômeno do envelhecimento populacional não é restrito ao Brasil, mas mundial. As projeções populacionais da Comissão Econômica para a América Latina e o Caribe (CEPAL, 2015) e do Banco Mundial, por exemplo, sugerem que Colômbia e Brasil são os países da América do Sul que apresentarão maior variação na razão dependência de idosos no período 2017-2030, embora atualmente os países sulamericanos com população mais envelhecida sejam Uruguai, Argentina e Chile. É um fato bastante conhecido que a velocidade de envelhecimento populacional no Brasil será bem superior àquela verificada em sociedades mais desenvolvidas no século passado (BIRD, 2011; TAFNER, 2012).

Uma maior população idosa em relação à população em idade ativa pressiona as contas públicas, especialmente as da previdência social, uma vez que a razão de dependência previdenciária está diretamente associada à razão de dependência populacional. De fato, os dados da Secretaria do Tesouro Nacional (STN) mostram que as despesas com benefícios previdenciários do RGPS, que não inclui o regime dos servidores públicos civis e militares, têm crescido mais rápido que o total das despesas primárias do Governo Central. Com isso, a razão entre a despesa com os benefícios previdenciários (somando-se urbano e rural) e a despesa primária total do Governo Central subiu de 35,3\% (ou 4,9\% do PIB) em 1997 para 43,8\% (ou 8,6\% do PIB) nos últimos 12 meses, encerrados em junho de 2018. Esse comportamento crescente das despesas previdenciárias ao longo do tempo tem gerado um desequilíbrio estrutural no saldo previdenciário. Isso ocorre porque ainda que a

\footnotetext{
${ }^{2}$ A abordagem realizada por Caetano (2006a) considera as seguintes variáveis para o cálculo da sustentabilidade do sistema previdenciário e para a análise comparativa entre países: i) a relação entre o número de contribuintes e beneficiários (razão de dependência previdenciária); ii) a taxa de reposição média do regime previdenciário (razão entre o valor médio do benefício previdenciário e o salário médio de contribuição para a previdência); e iii) a alíquota média de contribuição previdenciária. Umas das principais conclusões dessa análise comparativa (p. 31) é que "o RGPS brasileiro é distante e muito mais generoso do que os congêneres de outras nações".
} 
alíquota de contribuição do RGPS seja uma das mais altas do mundo ${ }^{3}$, o comportamento da arrecadação previdenciária líquida ${ }^{4}$ não tem acompanhado o da despesa previdenciária.

Os dados da Secretaria de Políticas de Previdência Social do Ministério da Fazenda revelam que o déficit do RGPS já ultrapassa a marca dos 190 bilhões de reais (2,5\% do PIB) no acumulado dos 12 meses encerrados em junho de 2018. Se levarmos em conta que cerca de 30 milhões de benefícios previdenciários e acidentários têm sido pagos, o déficit per capita tem sido da ordem de R\$ 6.300 em 12 meses. Esse déficit é especialmente problemático, pois tem superado, em valor absoluto, o superávit do Tesouro Nacional e do Banco Central (desde 2015). Um déficit previdenciário cada vez maior implica, neste contexto, que o comportamento das despesas e receitas do RGPS tem retirado espaço fiscal que poderia ser utilizado em outras políticas públicas meritórias ou mesmo em outros investimentos públicos.

Déficit previdenciário elevado não implica, necessariamente, que as contas previdenciárias são financeiramente insustentáveis. Nem mesmo testes de estacionariedade da série do déficit previdenciário ou testes de cointegração entre a despesa e a receita previdenciária nos permitem obter uma conclusão estatisticamente rigorosa acerca da insolvência do RGPS. Nesse contexto, a função de reação fiscal proposta por Bohn $(1998,2007)$ tem sido utilizada como uma forma adequada de se analisar empiricamente a solvência intertemporal do setor público e das contas previdenciárias, uma vez que o setor previdenciário é um subconjunto do setor público. Levando isso em conta, o objetivo principal deste artigo é apresentar a dinâmica demográfica do Brasil, chamando atenção para o envelhecimento da população e para seus possíveis efeitos nas contas previdenciárias, além de testar a sustentabilidade do RGPS utilizando o arcabouço da função de reação fiscal de Bohn (1998, 2007).

\footnotetext{
3 No RGPS, a soma entre as alíquotas pagas pelo segurado e pelo empregador é 31\% dos salários (11\% do segurado e $\mathbf{2 0} \%$ do empregador). Na comparação internacional feita por Caetano (2006a, p. 24), somente a Itália possui alíquota de contribuição previdenciária superior à alíquota do RPGS.

4 Neste trabalho, a arrecadação previdenciária líquida é definida como o somatório da arrecadação das contribuições dos trabalhadores e empregadores do setor privado, deduzidos os valores transferidos a terceiros - principalmente aos órgãos do Sistema S - e deduzidas também das restituições de arrecadação e ressarcimentos. Outras receitas próprias também entram nesse cálculo, embora sejam pouco expressivas. Os dados da arrecadação previdenciária líquida são mensalmente divulgados pela STN no Resultado do Tesouro Nacional desde 1997. Dados desagregados para os setores rural e urbano, entretanto, só são disponíveis a partir de 2001. Vale ressaltar, por outro lado, que o art. 195 da Constituição Federal prevê que a seguridade social deve ser financiada por toda a sociedade e, neste caso, para além das receitas de contribuições previdenciárias dos trabalhadores e empregadores do setor privado, a Constituição estabelece outras contribuições sociais (CSLL, Cofins e receitas de concursos de prognósticos) para financiar o sistema de seguridade social.
} 
Rocha (1997), Simonassi e Arraes (2007), Mello (2007), Campos e Cysne (2019) e Jesus (2019) utilizaram esse arcabouço analítico e estimaram versões da função de reação fiscal com dados agregados da economia brasileira5. Matos, Melo e Simonassi (2013), Koury (2014) e Macedo, Jesus e Drumond (2018) se apropriaram dessa literatura e aplicaram a noção de resposta fiscal para os dados do RGPS e para os regimes próprios da previdência social (RPPS) dos servidores públicos do estado do Ceará e da Bahia, respectivamente. Este artigo segue de perto esses três últimos trabalhos e estende o modelo empírico estimado pelos autores adicionando duas variáveis relevantes na equação do saldo previdenciário do setor público: uma para capturar a influência do ciclo econômico, o hiato do produto, e outra para considerar a dinâmica demográfica, a razão de dependência de idosos (ou a taxa de crescimento da razão de dependência de idosos).

Além da introdução, este trabalho é composto por mais três partes. Na parte 2, utilizam-se dados das projeções (populacionais e previdenciárias) de longo prazo realizadas por órgãos oficiais, para se apresentar um breve panorama da dinâmica demográfica e o desafio previdenciário no Brasil. Na parte 3, é descrito o modelo empírico, os dados e os resultados das estimativas econométricas, bem como os exercícios de sensibilidade do modelo de referência. Na parte final, são sumarizadas as principais conclusões e algumas implicações dos resultados obtidos são aventadas.

\section{Demografia e Previdência Social no Brasil}

O envelhecimento da população pode ser entendido como um fenômeno global. Um indicador que sustenta essa afirmação é a idade mediana da população de diversos países, que tende a convergir ao longo do tempo, salvo algumas exceções. As projeções populacionais do Department of Economic and Social Affairs da Organização das Nações Unidas (ONU, 2017) revelam que, em 2015, a idade mediana nos países da América do Norte era oito anos maior que a idade mediana nos países da América do Sul, e que no ano de 2050 essas idades serão praticamente iguais (42 anos). Estas projeções também revelam que as idades medianas na Ásia, América Latina e Caribe, Europa e América do Norte serão bem próximas em 2050.

Estima-se que em 2050 a idade mediana da população brasileira seja de 45 anos, contra uma idade mediana de apenas 19 anos em 1950. Com isso, espera-se que, em 2050, o Brasil possua uma população mais envelhecida que as populações dos Estados Unidos, Reino Unido, França, Noruega, Suécia, Austrália e Nova Zelândia, países já desenvolvidos e que atualmente possuem uma estrutura etária mais

5 Para o caso de economias desenvolvidas consultar, dentre outros, Galí e Perotti (2003), Ghosh et al (2013) e Everaert e Jansen (2018). 
envelhecida que a brasileira. Outro fenômeno demográfico importante no Brasil, também ligado ao envelhecimento populacional, é a esperança de vida ao nascer, que saltou de 51 anos em 1950 para 74 anos em 2010, e deve atingir 81 anos em 206o.

Os dados da projeção populacional revisada pelo IBGE em 2018 reforçam o diagnóstico de que a estrutura demográfica brasileira tem mudado muito rapidamente. Além do aumento da idade mediana da população e da esperança de vida ao nascer, outros fatos estilizados extraídos da projeção populacional do IBGE para as próximas décadas são:

i) diminuição da taxa de fecundidade total de 1,76 em 2020 para 1,66 em 206o;

ii) diminuição da razão entre o número de nascimentos e de óbitos de 2,13 em 2020 para 0,74 em 2060;

iii) aumento no índice de envelhecimento ${ }^{6}$ de $46,9 \%$ em 2020 para $173,5 \%$ em 2060;

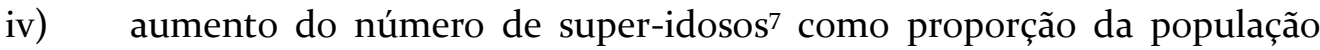
total, de $0,98 \%$ em 2020 para 4,61\% em 2060;

v) aumento da razão de dependência de idosos ${ }^{8}$ de $14 \%$ em 2020 para $43 \%$ em 2060;

vi) diminuição do número de pessoas em idade ativa para cada idoso - de 7,3 em 2020 para apenas 2,3 em 206o.

As explicações para essa mudança demográfica em curso perpassam a melhora da saúde da população, tal como o acesso à água tratada e a avanços na medicina, e também por mudanças comportamentais observadas no mundo moderno, tais como o aumento do grau de escolaridade da população, a difusão de métodos contraceptivos mais eficientes e a maior inserção da mulher no mercado de trabalho. Os efeitos dessa transformação demográfica podem ser facilmente observados na pirâmide etária brasileira, que tem deixado de apresentar o formato triangular (o que é comum em países em desenvolvimento) e está se transformando em uma espécie de trapézio.

A taxa de crescimento populacional, que era de $3 \%$ ao ano na década de 1960 , passará a ser negativa a partir de 2047, ano em que o país terá pouco mais de 233 milhões de habitantes, segundo as projeções do IBGE. No entanto a taxa de crescimento para cada grupo etário (e também para cada gênero) será diferente. A população idosa crescerá mais rápido que a população em idade ativa, a população infantil decrescerá e a população idosa feminina será entre $30 \%$ e $33 \%$ maior que a

\footnotetext{
${ }^{6}$ População com 65 anos ou mais dividido pela população entre o e 14 anos.

7 Pessoas com 85 anos ou mais de idade.

${ }^{8}$ Razão entre a população com idade igual ou superior a 65 anos e a população com idade entre 15 e 64 anos (população em idade ativa).
} 
população idosa masculina. De fato, a taxa de crescimento da população idosa será superior a 3\% ao ano até 2034 , a taxa de crescimento da população em idade ativa passará a ser negativa a partir de 2037, e a razão entre mulheres e homens idosos crescerá quase continuamente até 2041.

Figura 1: Evolução populacional por grupos etários (em milhões): 2020-2060

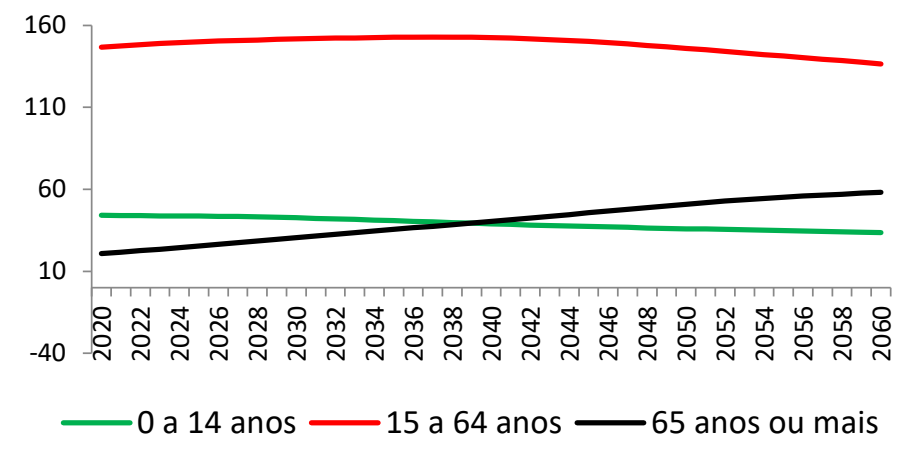

Fonte: IBGE. Projeção da População (2018)

Na Figura 1 tem-se a evolução populacional por grupos etários para o período 2020-2060. Nesta figura, pode-se observar claramente que o hiato entre a população em idade ativa e a população idosa tende a diminuir a cada ano já a partir de 2021, de modo que a diferença entre esses dois grupos etários passará de 126 milhões de pessoas em 2020 para 78 milhões de pessoas em 2060. Entre 2020 e 2060, espera-se que a população idosa cresça $179,5 \%$, enquanto a população em idade ativa caia $7 \%$, e a população infantil, $24 \%$. Além disso, vale mencionar que essa transição demográfica tem sido mais intensa do que se esperava há 14 anos: em 2004, o IBGE projetava que o Brasil teria 164 milhões de pessoas em idade ativa em 2050, enquanto na revisão de 2018 o IBGE projeta, também para 2050, uma população em idade ativa de apenas 146 milhões de pessoas.

Outro fato bastante conhecido é que a relação entre mulheres e homens tende a aumentar na medida em que o grupo etário se torna mais envelhecido. Esse movimento ocorre porque a diferença entre a probabilidade da morte de um homem em uma determinada idade e a probabilidade de morte de uma mulher nessa mesma idade é sempre positiva, e a diferença entre essas probabilidades é crescente com a faixa etária, especialmente a partir dos 15 anos de idade. A Figura 2 mostra a diferença entre a probabilidade de morte de mulheres e homens para cada par de indivíduos entre 40 e 79 anos. A consequência direta dessa diferença nas probabilidades é que a sobrevida da mulher em determinada idade adulta é persistentemente superior à sobrevida do homem para a mesma idade, o que gera 
uma assimetria a favor do número de mulheres no topo da pirâmide demográfica. De acordo com os dados da Tábua de Mortalidade do IBGE de 2016 (última disponível), aos 65 anos de idade espera-se que uma mulher tenha uma sobrevida de 20 anos, enquanto a expectativa de sobrevida do homem aos 65 anos é de apenas 16,8 anos.

\section{Figura 2: Diferença entre a probabilidade de morte de homens e de mulheres}

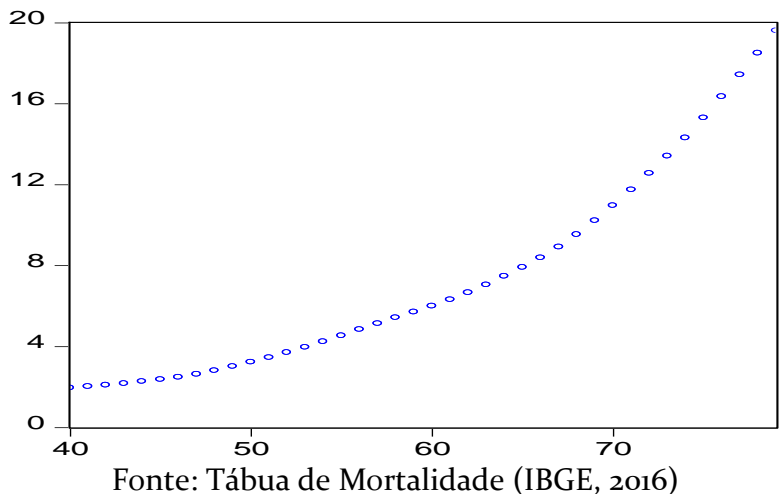

Nota: No eixo x são as idades e no eixo y as diferenças entre as prob. de morte (por mil).

Como o regime previdenciário brasileiro é de repartição simples (solidário), a população trabalhadora em idade ativa financia a população idosa aposentada. Além disso, como os critérios de elegibilidade para a concessão de benefícios previdenciários são diferentes para homens e mulheres, tem-se que as mulheres se aposentam, em média, mais cedo que os homens ${ }^{9}$. Assim, ao passo que a população idosa cresce como proporção da população ativa, a quantidade de contribuintes para cada beneficiado tende a cair e as despesas previdenciárias passam a ser constantemente pressionadas. De igual modo, maior população feminina acima de 60 anos causa mais despesas previdenciárias.

Portanto, se as regras atuais do sistema de aposentadorias permanecerem inalteradas, um cenário sombrio para as contas previdenciárias ao longo das próximas décadas pode ser projetado: a receita previdenciária deve permanecer mais

\footnotetext{
9 As mulheres, em geral, se aposentam mais cedo que os homens, e tendem a passar mais tempo recebendo o benefício. Espera-se que uma mulher que se aposentou por tempo de contribuição aos 50 anos de idade, por exemplo, receba o benefício por aproximadamente 32,5 anos. Neste caso, ela passa mais tempo sendo beneficiária do que contribuinte (30 anos de contribuição). Para um homem que se aposenta por tempo de contribuição, aos 55 anos, por outro lado, espera-se que ele receba o benefício por aproximadamente 24 anos, onze anos a menos do que o período de contribuição (35 anos de contribuição). Essa diferença é um reflexo da solidariedade entre os gêneros prevista no sistema previdenciário brasileiro. Para estatísticas mais detalhadas acerca da idade e do quantitativo de homens e mulheres aposentados por tempo de contribuição, consultar Costanzi e Ansiliero (2017, p. 40).
} 
ou menos constante, em proporção do PIB, e a despesa previdenciária deve aumentar sistematicamente, também em proporção do PIB. A Figura 3 mostra as projeções até 206o das receitas e despesas previdenciárias contidas no Projeto de Lei de Diretrizes Orçamentárias para o ano de 2019 (BRASIL, 2018, p. 58), enquanto na Figura 4 tem-se a projeção do déficit previdenciário para o mesmo período ${ }^{10}$.

\section{Figura 3: Projeção para as receitas e despesas previdenciárias (\% do PIB)}

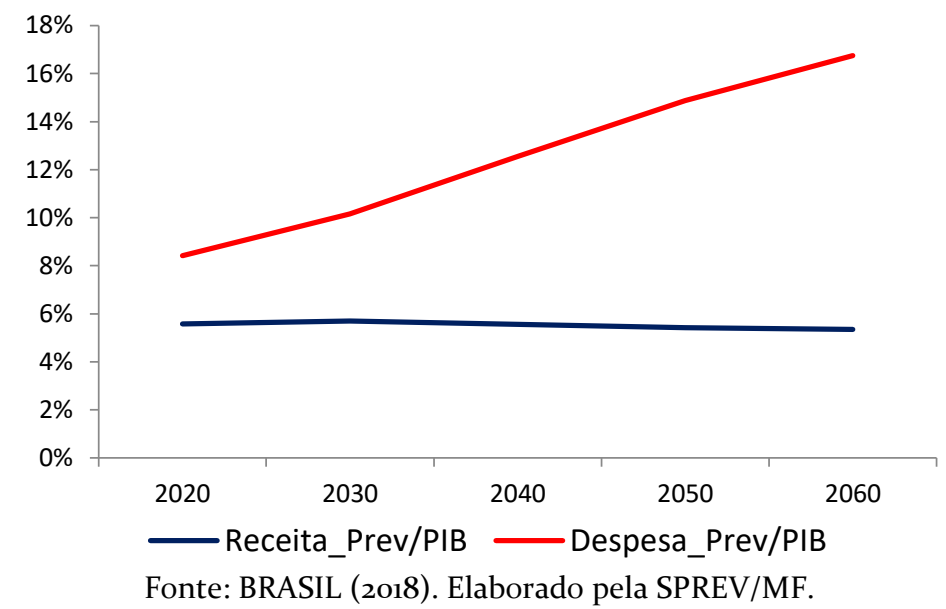

Nota-se nessas projeções que a receita previdenciária deve permanecer em torno de $5,5 \%$ do PIB ao longo do tempo, enquanto a despesa previdenciária deve aumentar cerca de oito pontos do PIB (algo como 608 bilhões de reais em valores atuais) entre 2020 e $2060^{11}$. O resultado direto desse descompasso entre receitas e despesas previdenciárias é um déficit crescente ao longo do tempo, que deve passar de pouco mais de $2,5 \%$ do PIB em 2020 para expressivos $11,4 \%$ do PIB em 2060.

1o Estas projeções foram realizadas com base em um modelo determinístico de projeção de receitas e despesas previdenciárias de longo prazo desenvolvido por técnicos do Tesouro Nacional, da Secretaria de Política Econômica do Ministério da Fazenda e com a equipe de Previdência Social do Instituto de Pesquisa Econômica Aplicada. Este modelo segue a boa prática internacional, tais como os modelos utilizados pelo Banco Mundial e pela Organização Internacional do Trabalho, e incorpora a legislação vigente do RGPS, inclusive as leis n. 13.135/15 e n. 13.183/15.

${ }^{11}$ Nas projeções obtidas a partir de um modelo mais simplificado que aquele descrito no PLDO (2018), Costanzi e Ansiliero (2017) sugerem que as despesas previdenciárias do RGPS e dos RPPS, somadas, devem aumentar 11 ou 11,7 pontos do PIB entre 2020 e 2060, e essa diferença deve-se ao uso de duas diferentes projeções populacionais: a do IBGE e a da ONU. O modelo simplificado utilizado por esses autores postula que a razão entre a despesa previdenciária e o PIB será afetada pela razão de dependência demográfica, pela taxa de ocupação no mercado de trabalho, pela cobertura previdenciária (número de beneficiários sobre a população de 55 anos ou mais de idade) e pela generosidade dos benefícios (valor do benefício médio em relação à produtividade média dos ocupados). 
Ressalta-se que essas previsões foram realizadas a partir de determinadas hipóteses sobre a dinâmica da demografia, do mercado de trabalho (taxa de participação, reajuste do salário mínimo), da macroeconomia (crescimento econômico, inflação, produtividade, reajustes do salário mínimo), bem como das regras atuais do sistema previdenciário brasileiro.

\section{Figura 4: Projeção para o déficit previdenciário (\% do PIB)}

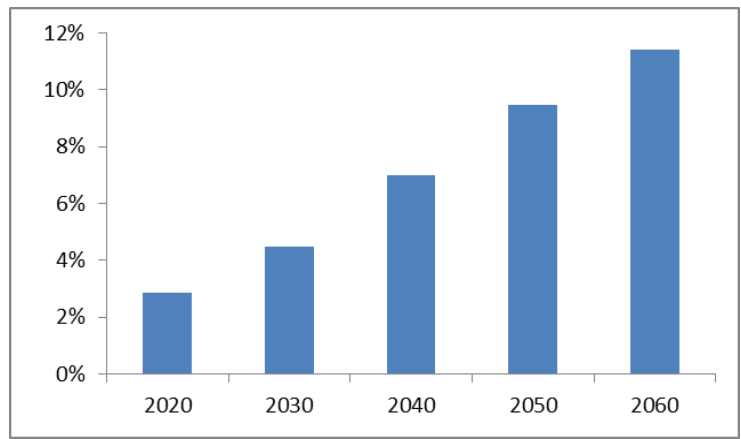

Fonte: BRASIL (2018). Elaborado pela SPREV/MF.

\section{Análise Empírica}

\subsection{Especificação do Modelo de Referência}

O modelo empírico de referência a ser testado parte da noção de função de reação fiscal, que foi originalmente sugerida por Bohn $(1998,2007)$ e, em seguida, adaptada para questões previdenciárias por Matos, Melo e Simonassi (2013), Koury (2014) e Macedo, Jesus e Drumond (2018). A função de reação adaptada assume o seguinte formato:

$$
s p_{t}=\beta_{0}+\beta_{1} e d p_{t-1}+\beta_{2} \widetilde{d p_{t}}+\beta_{3} \widetilde{r p}_{t}+\beta_{4} y_{t}+\beta_{5} r d_{t}+\varepsilon_{t}
$$

De modo que $s p_{t}$ é o saldo previdenciário obtido por meio da diferença entre as receitas previdenciárias, $r p_{t}$, e as despesas previdenciárias, $d p_{t}$; $e d p_{t-1}$ é o estoque da dívida previdenciária; $\widetilde{d p_{t}}$ corresponde ao desvio percentual da despesa previdenciária em relação à sua tendência de longo prazo; $\widetilde{r p}_{t}$ representa o desvio percentual da receita previdenciária também em relação à sua tendência; $y_{t}$ é o hiato do produto; $r d_{t}$ é a razão de dependência de idosos; e $\varepsilon_{t}$ é o termo de erro estocástico i.i.d.

A diferença fundamental entre o modelo (1) e o especificado pelos autores acima citados está na incorporação de duas importantes variáveis que ajudam a explicar o saldo previdenciário em determinado momento do tempo: o hiato do 
produto e a razão de dependência de idosos. Se, por exemplo, assumirmos que o saldo previdenciário é contracíclico, então o coeficiente do hiato do produto $\left(\beta_{4}\right)$ deverá ser positivo. Esse resultado é o esperado porque quando o hiato do produto é negativo (como em uma desaceleração ou em uma recessão), há um menor contingente de pessoas no mercado de trabalho formal contribuindo compulsoriamente para a previdência social. Essa contração na receita previdenciária, associada com a não redução do número de beneficiários, implica uma redução do saldo previdenciário. Espera-se, por outro lado, que o sinal do coeficiente da razão de dependência de idosos $\left(\beta_{5}\right)$ seja negativo, uma vez que quanto maior o número de idosos como proporção da população em idade ativa, maior também deve ser a razão de dependência previdenciária (a relação beneficiários/contribuintes) e, portanto, menor deve ser o saldo previdenciário.

Os sinais esperados para os demais coeficientes da equação (1) são os seguintes: $\beta_{2}<0$ e $\beta_{3}>0$, uma vez que o saldo previdenciário deve diminuir quando a despesa previdenciária está acima de sua tendência de longo prazo, e o saldo previdenciário deve aumentar quando a receita previdenciária está acima da sua tendência. Para que a condição de sustentabilidade do regime previdenciário seja satisfeita, é necessário que $\beta_{1}>0$, ou seja: o saldo previdenciário deve melhorar depois de observado um aumento da dívida previdenciária no período anterior. Se, caso contrário, o saldo previdenciário se deteriorar depois de observado um aumento na dívida previdenciária, com todas as demais variáveis permanecendo constantes, tem-se que o déficit previdenciário é financeiramente insustentável. Portanto a principal informação do modelo explicitado em (1) é aquela relacionada ao sinal e à significância estatística do coeficiente $\beta_{1}$.

Os coeficientes da função de reação fiscal adaptada serão estimados por meio de três métodos diferentes: mínimos quadrados ordinários (QMO), regressões quantílicas (RQ) e mínimos quadrados robustos (MQR). A equação (1) será estimada para o período completo e também considerando o caso de janelas móveis de 60 trimestres fixos. Nas estimações com janelas móveis, uma atenção especial será dada ao parâmetro $\beta_{1}$, pois se deseja saber se o parâmetro que indica a sustentabilidade do sistema previdenciário sofreu alteração significativa ao longo do tempo.

\subsection{Dados}

Os dados utilizados para a estimação do modelo de referência possuem periodicidade trimestral e cobrem o período 1998T1-2018T1, totalizando 81 observações. Períodos anteriores a 1998 não foram considerados devido à inexistência de uma base de dados homogênea para todas as variáveis de interesse. Optou-se por utilizar dados trimestrais em vez de dados mensais ou anuais porque 
dados mensais possuem muitos ruídos e uma base com dados anuais seria muito pequena (com apenas 20 observações).

A receita previdenciária é a arrecadação líquida para o RGPS dividida pela receita total do Governo Central, enquanto a despesa previdenciária é a soma dos benefícios previdenciários pagos aos trabalhadores urbanos e rurais ${ }^{12}$, também dividida pela receita total do Governo Central. Ressalta-se que as despesas com os benefícios de prestação continuada (BPC) da Lei Orgânica da Assistência Social (Loas) e a Renda Mensal Vitalícia (RMV), que representam 9,6\% das despesas previdenciárias no acumulado dos 12 meses encerrados em junho de 2018 , não foram computadas como despesas previdenciárias, visto vez que a natureza desses benefícios é essencialmente assistencial. O saldo previdenciário, por seu turno, é definido como a diferença entre a receita líquida para o RGPS e os benefícios previdenciários, e também está normalizada pela receita total do Governo Central ${ }^{13}$. Essas três variáveis estão em valores constantes de maio/2018 (atualizados pelo IPCA) e foram coletadas em periodicidade mensal junto ao Resultado do Tesouro Nacional da STN (2018). Na sequência, as variáveis receita previdenciária, despesa previdenciária e saldo previdenciário, todas como proporção da receita total do governo, foram trimestralizadas por meio de média simples e dessazonalizadas pelo método Census X-12. O comportamento das tendências da receita e da despesa previdenciária como proporção da receita total do governo pode ser observado na Figura 5, enquanto o déficit previdenciário (negativo do saldo previdenciário) tanto em proporção da receita total quanto em proporção do PIB $^{14}$ - pode ser visto na Figura 6. Os componentes cíclicos das receitas e despesas previdenciárias como proporção da receita total foram calculados como o desvio percentual dessas

\footnotetext{
${ }_{12}$ As despesas com os benefícios previdenciários do setor urbano têm oscilado em torno de $78 \%$ das despesas totais do RGPS (urbano mais rural). No entanto, quando o déficit do RGPS é desagregado, nota-se que a contribuição maior tem sido a do déficit do setor rural: 65,7\% do déficit do RGPS em 2017 deveu-se ao setor rural. A maior contribuição para o déficit do RGPS é a do setor rural, já que, nesse setor, a arrecadação tem sido muito pequena (menos de 10 bilhões de reais em 2017, em valores correntes) em relação ao montante de benefícios pagos (120 bilhões de reais em 2017, em valores correntes). Enquanto no setor urbano a arrecadação previdenciária correspondeu a $85,9 \%$ da despesa com benefícios previdenciários em 2017, essa relação para o setor rural foi de apenas $7,8 \%$. Como a quantidade de beneficiários do setor rural é bem menor que a quantidade de beneficiários do setor urbano (9,5 milhões contra 20,5 milhões, em 2017, respectivamente), o hiato entre o déficit per capita do setor rural e o déficit per capita do setor urbano é ainda mais expressivo. Em 2017, esse hiato foi de $233 \%$ em favor do déficit da previdência rural.

$13 \mathrm{O}$ saldo previdenciário considera o pagamento de sentenças judiciais e a Compensação Previdenciária (Comprev) entre o Instituto Nacional do Seguro Social (INSS) e os Regimes Próprios de Previdência Social (RPPS) dos estados e municípios, além das renúncias previdenciárias (Simples Nacional, entidades filantrópicas, microempreendedor individual e exportação da produção rural).

${ }^{14}$ PIB extraído do Sistema de Séries Temporais do Banco Central do Brasil. A correlação entre o déficit previdenciário normalizado pelo PIB e o normalizado pela Receita Total do Governo Central é o,99.
} 
variáveis em relação às suas tendências de longo prazo, que foram calculadas por meio do filtro Hodrick-Prescott $(\lambda=1600)$.

Figura 5: Tendência das despesas e receitas previdenciárias

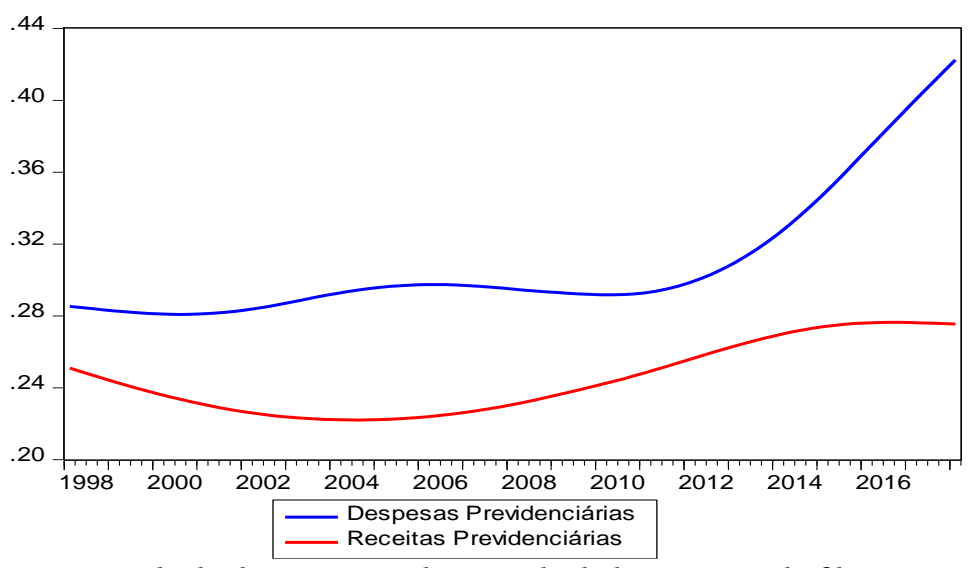

Fonte: cálculo do autor. Tendência calculada por meio do filtro HP.

A variável dívida previdenciária não é disponibilizada nas estatísticas fiscais do governo e teve que ser calculada. Para tanto, utilizou-se um procedimento similar àquele realizado por Matos, Melo e Simonassi (2013): acumulou-se o déficit previdenciário nos 12 últimos meses e este foi dividido pela receita total do governo, também acumulada nos 12 últimos meses. O valor da dívida previdenciária de jan/1998, por exemplo, é igual ao somatório do déficit previdenciário de fev/1997 a jan/1998, ao passo que o valor da dívida previdenciária no período seguinte corresponde ao somatório do déficit previdenciário de mar/1997 a fev/1998, e assim sucessivamente, até o período final da amostra (mar/2018). A transformação da série mensal para a série trimestral também foi feita por meio de médias simples. Vale destacar que os déficits passados acumulados (necessidade de financiamento) são análogos ao conceito de dívida pública do setor público, uma variável-chave monitorada tanto pelos agentes econômicos quanto pelos formuladores de política fiscal.

O hiato do produto é o desvio percentual do Produto Interno Bruto (PIB), calculado e disponibilizado (periodicidade trimestral) pelo IBGE em relação ao produto potencial, que é uma variável não observável. O nível de produto potencial foi calculado pelo método da função de produção, com metodologia detalhada em Souza-Júnior (2017). Os dados de produto potencial e hiato do produto estão publicamente disponíveis no site do Instituto de Pesquisa Econômica Aplicada (Ipea). 
Figura 6: Déficit previdenciário normalizado pela Receita Total e pelo PIB

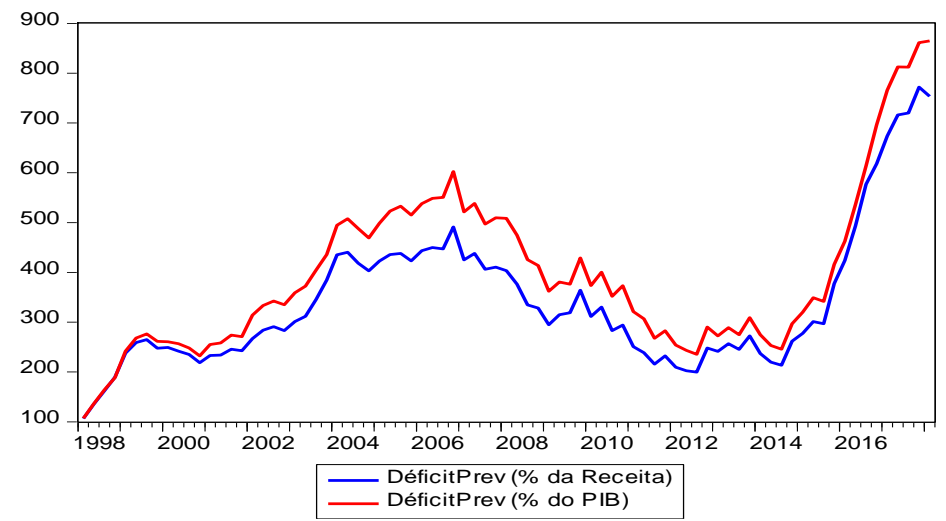

Fonte: Cálculo do autor. Média móvel de 12 meses, índice (1998T1=100).

A razão de dependência de idosos é a razão entre a população com idade igual ou superior a 65 anos e a população com idade entre 15 e 64 anos. Esses dados são oriundos da projeção populacional do Banco Mundial (WORLD BANK, 2017), já vez que a projeção atualizada do IBGE (2018) se inicia a partir do ano de 2010. Embora as tendências das projeções populacionais do IBGE e do Banco Mundial sejam similares, a projeção do IBGE para a razão de dependência de idosos no período 2010-2018 é levemente maior que a do Banco Mundial. As projeções do Banco Mundial sugerem que a razão de dependência de idosos no Brasil subiu de 7,6\% em 1998 para 12,7\% em 2018. Os dados da razão de dependência de idosos são anuais e foram transformados em trimestrais por meio de interpolação linear.

Todas as seis variáveis utilizadas no modelo de referência, já transformadas, podem ser visualizadas na Figura Aı no Apêndice.

\subsection{Resultados}

Na estimação por MQO, o erro-padrão associado a cada coeficiente é robusto à heterocedasticidade (método de covariância de Huber-White), a regressão quantílica foi estimada para a mediana (coeficiente de covariância Huber Sandwich), e os coeficientes da regressão robusta foram obtidos por meio do método de estimação $\mathrm{M}$, que é robusto à presença de outliers na variável dependente. Os principais resultados dessas três estimativas econométricas podem ser vistos na Tabela 1.

Os coeficientes dos componentes cíclicos das despesas e receitas previdenciárias, do hiato do produto e da razão de dependência de idosos apresentam o sinal esperado e são sempre estatisticamente diferentes de zero aos 
níveis habituais de significância. Todos os modelos se ajustam bem aos dados, e todos os coeficientes são conjuntamente diferentes de zero. O coeficiente de interesse $\left(\beta_{1}\right)$ apresenta sinal negativo e é estatisticamente significante a $1 \%$, independentemente do método utilizado, com estimativa pontual variando muito pouco (entre -o,64 e-o,68). Isso significa que, tudo o mais permanecendo constante, o saldo previdenciário se deteriora em torno de -0,66\% quando a dívida previdenciária defasada aumenta em $1 \%$, o que é uma evidência em favor da insustentabilidade do déficit previdenciário no Brasil. Resultados similares a esses (exceto para a constante) foram encontrados por Matos, Melo e Simonassi (2013) utilizando dados mensais para o período 1990-2010 em um modelo que não leva em conta nem o ciclo econômico nem a razão de dependência.

Note-se ainda que em todas as estimativas o coeficiente da razão de dependência de idosos é maior (em valor absoluto) que o coeficiente do hiato do produto. Ademais, todas as estimativas se ajustam bem aos dados, sendo que em duas delas o coeficiente de determinação ajustado é maior que o,9. Esses resultados não mudam muito quando uma dummy de intercepto é adicionada ao modelo para períodos de recessão ${ }^{15}$ (consultar a Tabela A1 no Apêndice). Nesse caso, o parâmetro da variável dummy é negativo e significativo em todas as estimativas, o da dívida previdenciária aumenta para o intervalo $(-0,76 \mathrm{a}-0,80)$ e o do hiato do produto diminui para o intervalo (o,19 a o,23).

Quando o hiato do produto e a razão de dependência de idosos são omitidas das estimativas, o principal resultado (não reportado) também não é qualitativamente alterado, mas o sinal da constante passa a ser negativo e o coeficiente da dívida previdenciária se aproximaria de -1 em todas as estimativas. Por outro lado, quando os componentes cíclicos da receita e da despesa previdenciária são omitidos do modelo (resultado não reportado), o coeficiente do hiato do produto passa para o intervalo o,52 a o,57 e o da dívida previdenciária para o intervalo -0,70 a -0,74. As estimativas pontuais dos parâmetros obtidos por mínimos quadrados ordinários praticamente não são alteradas quando o modelo é estimado por meio de variáveis instrumentais ${ }^{16}$

\footnotetext{
15 Utilizou-se a cronologia do ciclo de negócios brasileiros do Comitê de Datação dos Ciclos Econômicos (CODACE) para definir os períodos de recessão. A variável dummy assume valor 1 para os trimestres em que a economia esteve em recessão e o em caso contrário. No período, de acordo com a definição utilizada, a economia brasileira passou por cinco recessões distintas, totalizando 23 trimestres $(28,4 \%$ da amostra).

${ }^{16}$ A função de reação fiscal adaptada foi estimada também por meio de variáveis instrumentais, uma vez que é possível argumentar que o hiato do produto é uma variável endógena (o saldo previdenciário também pode afetar o hiato do produto por meio do multiplicador fiscal). Utilizou-se a primeira e a segunda defasagem do hiato do produto como instrumentos na regressão do primeiro estágio, tal como Everaert e Jansen (2018), mas optou-se por não reportar os resultados porque eles são praticamente
} 
Tabela 1: Variável dependente: saldo previdenciário

\begin{tabular}{|c|c|c|c|}
\hline & MQO & RQ & MQR \\
\hline Constante & $\begin{array}{c}0,03^{*} \\
(0,005)\end{array}$ & $\begin{array}{c}0,03^{*} \\
(0,007)\end{array}$ & $\begin{array}{c}0,03^{*} \\
(0,006)\end{array}$ \\
\hline$e d p_{t-1}$ & $\begin{array}{l}-0,64^{*} \\
(0,051)\end{array}$ & $\begin{array}{l}-0,66^{*} \\
(0,070)\end{array}$ & $\begin{array}{c}-0,68^{*} \\
(0,049)\end{array}$ \\
\hline$\widetilde{d p_{t}}$ & $\begin{array}{l}-0,28^{*} \\
(0,038)\end{array}$ & $\begin{array}{l}-0,22^{*} \\
(0,070)\end{array}$ & $\begin{array}{c}-0,23^{*} \\
(0,025)\end{array}$ \\
\hline$\widetilde{r p}_{t}$ & $\begin{array}{c}0,22^{*} \\
(0,042)\end{array}$ & $\begin{array}{l}0,15^{* *} \\
(0,065)\end{array}$ & $\begin{array}{c}0,17^{*} \\
(0,035)\end{array}$ \\
\hline$y_{t}$ & $\begin{array}{c}0,33^{*} \\
(0,053)\end{array}$ & $\begin{array}{l}0,40^{*} \\
(0,07)\end{array}$ & $\begin{array}{c}0,37^{*} \\
(0,052)\end{array}$ \\
\hline$r d_{t}$ & $\begin{array}{l}-0,55^{*} \\
(0,072)\end{array}$ & $\begin{array}{c}-0,51^{*} \\
(0,089)\end{array}$ & $\begin{array}{l}-0,48^{*} \\
(0,065)\end{array}$ \\
\hline $\mathrm{R}^{2}\left(\mathrm{R}_{\mathrm{W}}\right)$ ajust. & 0,94 & 0,73 & 0,96 \\
\hline
\end{tabular}

Notas: $\left({ }^{*}\right)$ e $\left({ }^{* *}\right)$ estatisticamente significante a $1 \%$ e $5 \%$.

Em parênteses estão os erro-padrões de cada coeficiente.

$\mathrm{Na}$ sequência, as estimativas por mínimos quadrados ordinários foram realizadas com janelas móveis de 60 períodos. Nessas novas estimativas, 21 conjuntos dos seis parâmetros foram obtidos, sendo que os parâmetros da dívida previdenciária defasada podem ser vistos na Figura 7, com o intervalo de confiança de $95 \%$. Nota-se que o coeficiente da dívida defasada é negativo e estatisticamente significante, independentemente da janela utilizada nas estimações. Esse coeficiente passa a ficar mais negativo quando os dados a partir do quarto trimestre de 2015 são incorporados ao modelo. Além disso, em todas essas novas estimativas o coeficiente de determinação ajustado é alto (variando de 0,83 a 0,95), todos os parâmetros são conjuntamente estatisticamente significantes, o coeficiente do hiato do produto é sempre positivo e significativo, e o da razão de dependência de idosos só passa a ser estatisticamente diferente de zero quando dados do período pós-2015 são considerados (consultar Figura A2 no Apêndice).

Os resultados das regressões com janelas móveis não são qualitativamente alterados quando a função de reação fiscal é estimada por meio de mínimos

idênticos àqueles obtidos por meio de mínimos quadrados ordinários, inclusive nas regressões com janelas móveis. 
quadrados robustos ou por regressões quantílicas. A Figura 8 permite a comparação visual das estimativas pontuais para o coeficiente da dívida previdenciária considerando os três métodos de estimação.

Os modelos estimados por mínimos quadrados robustos e por regressões quantílicas, entretanto, sugerem que, além do coeficiente da razão de dependência de idosos, o coeficiente do hiato do produto só é estatisticamente significante quando os dados dos últimos trimestres são considerados nas estimativas (resultados não reportados). De acordo com esses modelos, em geral, pode-se afirmar que o déficit previdenciário se tornou claramente contracíclico apenas em período recente, o que é um resultado compatível com Jesus (2019) para o caso das despesas previdenciárias, não parecendo haver evidências de que a razão de dependência de idosos era estatisticamente associada ao saldo previdenciário quando apenas se utilizavam dados do período anterior a 2015.

\section{Figura 7: Estimativas do parâmetro da dívida previdenciária (MQO)}

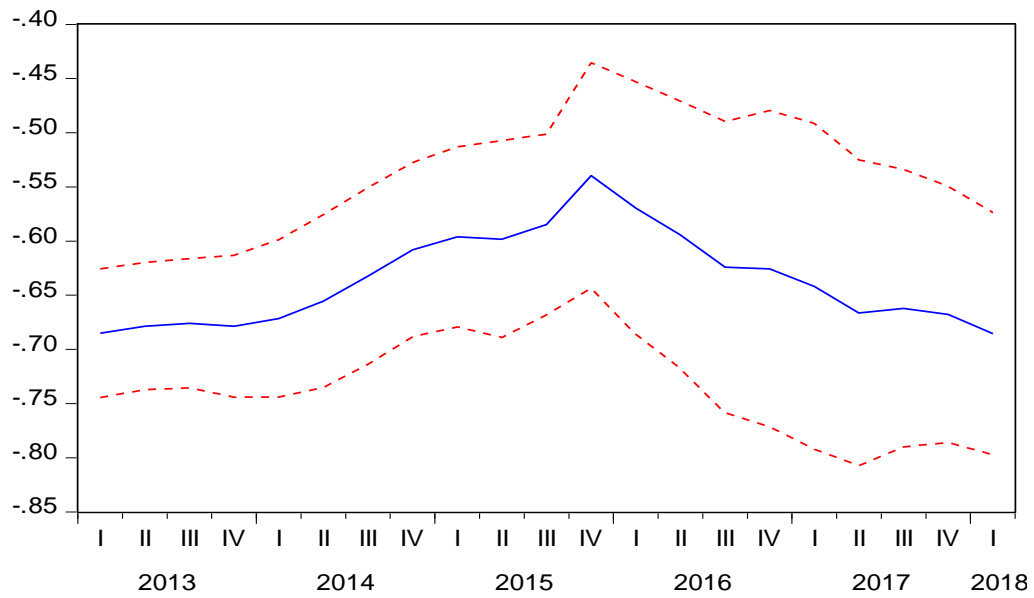

Fonte: cálculo do autor. Regressões com janelas móveis de 6o períodos. As estimativas referem-se ao modelo de referência.

A ausência de significância estatística para as estimativas do coeficiente da razão de dependência de idosos em algumas sub-amostras é de chamar atenção, pois se esperava que esse parâmetro fosse negativo e significativo independentemente do período utilizado para a estimação. Levando isso em conta, optou-se por calcular a taxa de crescimento da razão de dependência e utilizá-la na equação (1), ao invés da variável em nível $\left(r d_{t}\right)$. A taxa de crescimento é calculada em relação ao nível observado em $t-4$, de modo que as quatro observações iniciais são perdidas nesta especificação alternativa. A partir da análise dos dados dessa nova variável notou-se que nos últimos onze anos a razão de dependência de idosos tem acelerado 
continuamente o seu crescimento, passando de 1,99\% ao ano, em 20o8, para impressionantes 3,66\% ao ano, em 2018.

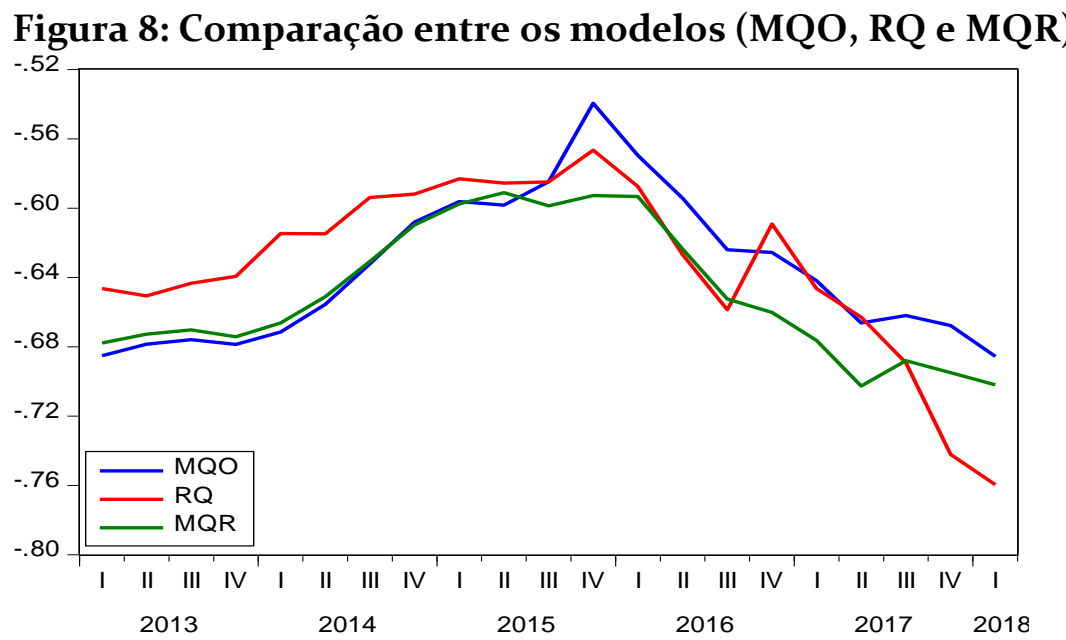

Fonte: cálculo do autor. Regressões com janelas móveis de 6o períodos.

\section{Figura 9: Estimativas do parâmetro da dívida previdenciária (MQO) \\ Rolling Coefficients with Confidence bands}

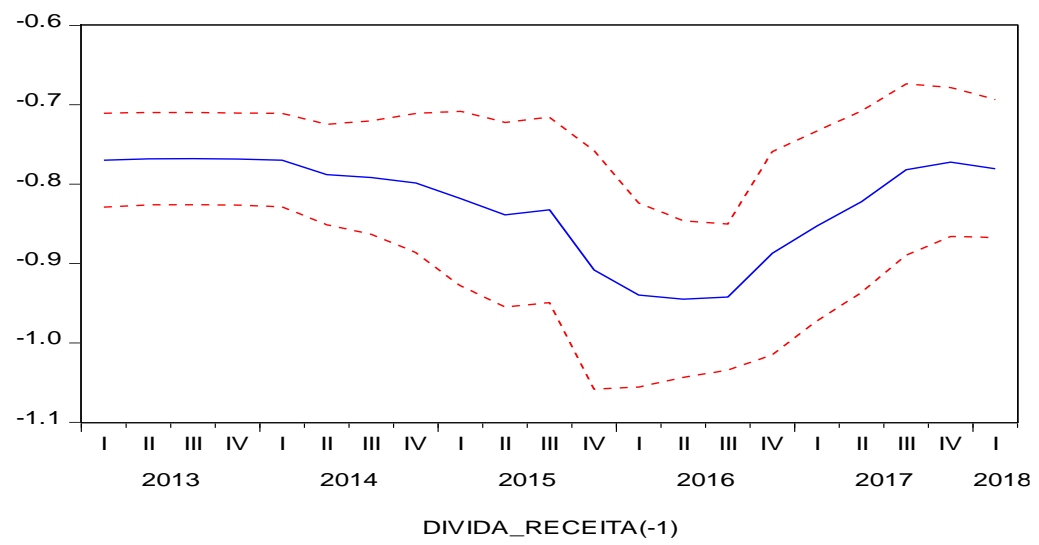

Fonte: cálculo do autor. Regressões com janelas móveis de 6o períodos. As estimativas referem-se ao modelo de alternativo.

Os modelos estimados pelos três métodos aqui empregados são consistentes entre si, e sugerem que o sinal da taxa de crescimento da razão de dependência de idosos é negativo e significativo a $1 \%$ (-1,67 na estimação por MQO). Os demais coeficientes permanecem com o mesmo sinal do modelo de referência ( $\beta_{1}=$ $-0,74 ; \beta_{2}=-0,31 ; \beta_{3}=0,24 ; \beta_{4}=0,24$, na estimação por $\mathrm{MQO}$ ) e também são 
significativos a $1 \%$. O mais importante é que as regressões com janelas móveis dessa nova especificação mostraram que: i) o coeficiente da taxa de crescimento da razão de dependência de idosos apresenta o sinal esperado, com significância estatística, independentemente da sub-amostra considerada; e ii) o coeficiente do hiato do produto é sempre positivo (ao redor de o,2), significativo e estável ao longo do tempo. A evolução do coeficiente da dívida defasada dessa nova especificação pode ser vista na Figura 9, abaixo, e a dos demais coeficientes, na Figura A3, no Apêndice.

\subsection{Robustez}

Com a finalidade de testar a robustez dos resultados acima reportados, optou-se por usar as seguintes definições alternativas das variáveis explicativas: i) hiato do produto calculado pela Instituição Fiscal Independente (IFI), também pelo método de função de produção (metodologia disponível em Orair e Bacciotti, 2018); ii) a razão de dependência de idosos, calculada com dados da projeção populacional do IBGE (2013) para o período 2000-2018, e da retroprojeção populacional também realizada pelo IBGE para o biênio 1998-1999; iii) a dívida líquida do setor público (em \% do PIB) disponibilizada pelo Banco Central do Brasil.

Em um primeiro momento, as novas variáveis foram utilizadas em regressões isoladas, totalizando nove novas estimativas (três para cada método de estimação). Em um segundo momento, considerou-se conjuntamente as novas proxies do hiato do produto e da razão de dependência de idosos (uma estimativa para cada método). Por fim, todas as três novas variáveis foram consideradas simultaneamente na função de reação fiscal adaptada, em substituição às suas variáveis correspondentes no modelo de referência, totalizando mais três novas estimativas (uma para cada método de estimação).

A análise dos coeficientes estimados nesses quinze novos modelos permitenos afirmar que os resultados do modelo de referência são robustos, pois os coeficientes de interesse permaneceram com os mesmos sinais reportados na Tabela 1 e todos eles (exceto a constante) se mostraram sempre estatisticamente significantes. O sinal negativo do coeficiente da dívida líquida do setor público significa que o déficit da previdência aumenta depois de uma variação positiva do endividamento do governo. Ressalta-se que esse comportamento das contas previdenciárias, dado seu peso na despesa primária do governo, contribui negativamente para o equilíbrio intertemporal das contas públicas como um todo.

Por fim, optou-se por estimar uma versão dinâmica da função de reação fiscal, adicionando-se um termo defasado do saldo previdenciário ao lado direito da equação (1), tal como apontado na função de reação fiscal especificada em Everaert 
e Jansen (2018) e Campos e Cysne (2019). A nova especificação assume o seguinte formato:

$$
s p_{t}=\theta_{0}+\theta_{1} s p_{t-1}+\theta_{2} e d p_{t-1}+\theta_{3} \widetilde{d p}_{t}+\theta_{4} \widetilde{r p}_{t}+\theta_{5} y_{t}+\theta_{6} r d_{t}+\varepsilon_{t}
$$

Nela, os parâmetros $\left[\theta_{2} \ldots \theta_{6}\right]$ agora são de curto prazo, pois supõe-se que o saldo previdenciário não se ajusta instantaneamente para determinado nível desejado. Para calcular os parâmetros de longo prazo, basta dividir cada parâmetro por $\left(1-\theta_{1}\right)$, caso o componente inercial do saldo previdenciário seja estatisticamente diferente de zero. As estimativas são realizadas considerando tanto a razão de dependência de idosos em nível $\left(r d_{t}\right)$ quanto em termos de taxa de crescimento $\left[g(r d)_{t}\right]$. Os resultados desta especificação dinâmica estão sumarizados na Tabela 2.

Tabela 2: Variável dependente: saldo previdenciário

\begin{tabular}{|c|c|c|c|c|c|c|}
\hline & MQO I & RQ I & MQR I & MQO II & RQ II & MQR II \\
\hline Constante & $\begin{array}{c}0,03^{*} \\
(0,007)\end{array}$ & $\begin{array}{l}0,02 * * \\
(0,009)\end{array}$ & $\begin{array}{c}0,02^{*} \\
(0,005)\end{array}$ & $\begin{array}{c}0,02^{*} \\
(0,004)\end{array}$ & $\begin{array}{c}0,02^{* *} \\
(0,004)\end{array}$ & $\begin{array}{c}0,02^{*} \\
(0,003)\end{array}$ \\
\hline$e d p_{t-1}$ & $\begin{array}{l}-0,55^{*} \\
(0,082)\end{array}$ & $\begin{array}{l}-0,56^{*} \\
(0,108)\end{array}$ & $\begin{array}{l}-0,47^{*} \\
(0,077)\end{array}$ & $\begin{array}{l}-0,72^{*} \\
(0,073)\end{array}$ & $\begin{array}{l}-0,64^{*} \\
(0,069)\end{array}$ & $\begin{array}{l}-0,64^{*} \\
(0,058)\end{array}$ \\
\hline$\widetilde{d p_{t}}$ & $\begin{array}{l}-0,28^{*} \\
(0,039)\end{array}$ & $\begin{array}{l}-0,21^{*} \\
(0,057)\end{array}$ & $\begin{array}{l}-0,22^{*} \\
(0,022)\end{array}$ & $\begin{array}{l}-0,31^{*} \\
(0,032)\end{array}$ & $\begin{array}{l}-0,28^{*} \\
(0,028)\end{array}$ & $\begin{array}{l}-0,26^{*} \\
(0,017)\end{array}$ \\
\hline$\widetilde{r p}_{t}$ & $\begin{array}{c}0,22^{*} \\
(0,040)\end{array}$ & $\begin{array}{c}0,15^{* *} \\
(0,062)\end{array}$ & $\begin{array}{c}0,18^{*} \\
(0,032)\end{array}$ & $\begin{array}{c}0,24^{*} \\
(0,029)\end{array}$ & $\begin{array}{c}0,24^{*} \\
(0,038)\end{array}$ & $\begin{array}{c}0,21^{*} \\
(0,024)\end{array}$ \\
\hline$y_{t}$ & $\begin{array}{c}0,30^{*} \\
(0,073)\end{array}$ & $\begin{array}{c}0,32^{*} \\
(0,106)\end{array}$ & $\begin{array}{c}0,24^{*} \\
(0,052)\end{array}$ & $\begin{array}{c}0,23^{*} \\
(0,045)\end{array}$ & $\begin{array}{c}0,21^{*} \\
(0,052)\end{array}$ & $\begin{array}{c}0,20^{*} \\
(0,036)\end{array}$ \\
\hline$r d_{t}$ & $\begin{array}{l}-0,52^{*} \\
(0,102)\end{array}$ & $\begin{array}{l}-0,41^{*} \\
(0,120)\end{array}$ & $\begin{array}{l}-0,37^{*} \\
(0,062)\end{array}$ & & & \\
\hline$g(r d)_{t}$ & & & & $\begin{array}{l}-1,65^{*} \\
(0,204)\end{array}$ & $\begin{array}{c}-1,24^{*} \\
(0,208)\end{array}$ & $\begin{array}{l}-1,28^{*} \\
(0,112)\end{array}$ \\
\hline$s p_{t-1}$ & $\begin{array}{c}0,11 \\
(0,121)\end{array}$ & $\begin{array}{c}0,15 \\
(0,139)\end{array}$ & $\begin{array}{c}0,28^{*} \\
(0,070)\end{array}$ & $\begin{array}{c}0,022 \\
(0,092)\end{array}$ & $\begin{array}{l}0,15^{* * *} \\
(0,077)\end{array}$ & $\begin{array}{c}0,16^{*} \\
(0,051)\end{array}$ \\
\hline $\mathrm{R}^{2}(\mathrm{Rw})$ ajust. & 0,94 & 0,73 & 0,96 & 0,97 & 0,81 & 0,98 \\
\hline
\end{tabular}

Notas: $\left({ }^{*}\right),\left({ }^{* *}\right)$ e $\left({ }^{* * *}\right)$ estatisticamente significante a $1 \%, 5 \%$ e $10 \%$.

Em parênteses estão os erro-padrões de cada coeficiente. 


\section{Conclusões e Implicações}

São quatro os fatos estilizados associados à dinâmica demográfica e às finanças públicas brasileiras: i) as taxas de fecundidade diminuíram muito rápido nas últimas décadas; ii) a população ainda é relativamente jovem, mas tem envelhecido muito rapidamente; iii) as despesas previdenciárias do RGPS têm aumentado sua participação nas despesas primárias totais do governo; iv) o déficit da previdência social é alto e estruturalmente crescente. Esses fatos estilizados são geralmente utilizados quando se discute a necessidade de reformas constitucionais na previdência social ${ }^{17}$. Este artigo partiu desses fatos e utilizou o arcabouço da função de reação fiscal para testar a sustentabilidade das contas previdenciárias (RGPS) no Brasil.

Os principais resultados dos exercícios empíricos realizados com dados do período 1998-2018 sugeriram que o déficit do RGPS é financeiramente insustentável, inclusive quando os modelos são estimados considerando diferentes sub-amostras. A situação de sustentabilidade financeira das contas previdenciárias exige que o saldo previdenciário melhore quando a dívida previdenciária defasada aumenta e as demais variáveis que influenciam o déficit previdenciário permanecem constantes, o que não foi o caso. Os resultados deste trabalho também mostraram que o déficit previdenciário é contracíclico no Brasil e que a razão de dependência de idosos, especialmente sua taxa de crescimento, é uma variável relevante na explicação do déficit previdenciário.

Se a tendência de forte deterioração do saldo previdenciário não for revertida, uma parcela cada vez maior da carga tributária terá que ser destinada ao pagamento de benefícios previdenciários, justamente como tem sido nos últimos anos. Isso implica que a fração de recursos financeiros que hoje é utilizada na provisão de bens públicos essenciais (saúde, educação e segurança pública, por exemplo) deve cair ao longo do tempo para que a restrição orçamentária intertemporal do governo seja respeitada e os preços macroeconômicos não sejam estruturalmente afetados. Além disso, sabe-se que a dinâmica da poupança, a acumulação de capital físico e a taxa de crescimento potencial da economia dependem da adequação das contas públicas à nova realidade demográfica do país.

A implicação direta das conclusões aqui obtidas é que a estrutura do regime previdenciário no Brasil não deve permanecer inalterada ao longo da década de 2020. Do ponto de vista técnico, as reformas possíveis podem ser divididas em dois

17 Alguns critérios norteadores para uma agenda de reformas podem ser encontrados em Tafner (2012). 
grandes blocos: as estruturais e as paramétricas. As mudanças estruturais referemse à forma de financiamento do sistema previdenciário (de repartição para capitalização, por exemplo), enquanto as mudanças paramétricas são baseadas essencialmente em quatro elementos: alíquotas de contribuição, condições de qualificação, fórmula de cálculo do benefício e sua regra de indexação (CAETANO, 2006b). Qualquer tipo de reforma no sistema de previdência social é algo politicamente complicado em uma democracia, por razões óbvias, e o prazo necessário para que o saldo previdenciário seja afetado depende do tipo e da profundidade da reforma que é implementada.

Por um lado, uma mudança estrutural no RGPS tende a resolver o problema da insustentabilidade do déficit previdenciário no longo prazo, mas o custo fiscal da transição para o novo regime não é desprezível. Isso ocorre porque, mesmo com a implementação de um sistema privado de capitalização de contas individuais, o governo ainda arcaria com o custo do pagamento aos atuais beneficiários do regime de repartição, que possuem direitos constitucionais adquiridos, mas não obteria a receita oriunda dos novos contribuintes, já que suas contribuições seriam destinadas para o financiamento de suas próprias aposentadorias no futuro. Por outro lado, as mudanças paramétricas no RGPS têm capacidade de afetar positivamente o resultado previdenciário no curto e no médio prazo (a partir de um aumento imediato nas alíquotas de contribuição, da alteração dos critérios de elegibilidade para a concessão de aposentadorias, da alteração na taxa de reposição, dentre outras mudanças). No entanto sabe-se que mudanças paramétricas exigem que novas reformas no sistema de previdência social sejam realizadas ao longo do tempo, à medida que a população envelhece e a arrecadação deixa (novamente) de acompanhar as despesas previdenciárias.

Os impactos sociais de reformas previdenciárias, estruturais ou paramétricas, são incertos e dependem fundamentalmente do desenho das reformas que serão implementadas e de como os agentes privados responderão aos novos incentivos. Uma reforma paramétrica com potencial de afetar positivamente a saúde das finanças públicas e que, ao mesmo tempo, não concentre os custos da mudança nos grupos historicamente menos favorecidos envolve, dentre outras coisas: i) a extinção da aposentadoria por tempo de contribuição; ii) a imposição de idade mínima móvel (não necessariamente iguais) para homens e mulheres; iii) o aumento da alíquota de contribuição para setores que são atualmente subtributados (como ruralistas e microempresas, por exemplo); e iv) a mudança gradual do sistema de previdência de todos os servidores públicos, inclusive dos militares.

Caso a reforma paramétrica no sistema de previdência social seja focalizada na desvinculação do piso do benefício ao salário mínimo vigente, na adoção de regras bem mais rígidas para os trabalhadores rurais e na adoção de idade mínima móvel para a concessão do benefício apenas para os trabalhadores do setor privado, 
espera-se que a parcela da sociedade historicamente mais favorecida arque com um custo relativamente mais baixo no processo de ajuste. Se esse for o caso, a desigualdade social deverá se aprofundar ao longo do tempo, ou diminuir menos do que no cenário alternativo, o que não é desejável. Nesta perspectiva, acredita-se que, para o atual contexto da economia brasileira, uma reforma paramétrica desenhada em linha com a Proposta de Emenda à Constituição n. 287 (PEC 287), já discutida na Câmara dos Deputados e aprovada em comissão especial (o substitutivo, em maio de 2017), é mais adequada do que uma reforma estrutural que crie contas individuais para todos os trabalhadores do setor privado. A PEC 287 tem o mérito de contribuir para o necessário ajuste fiscal estrutural e, ao mesmo tempo, preserva a solidariedade do sistema previdenciário brasileiro. Cabe ressaltar que uma eventual instituição de contas individuais para todos os trabalhadores e a adoção de um regime de capitalização, embora tenha o potencial de ser atuarialmente equilibrado, sepultaria o atual regime solidário de previdência social.

\section{Referências}

BANCO MUNDIAL. Um Ajuste Justo - Análise da Eficiência e Equidade do Gasto Público no Brasil, Volume I: Síntese, nov. 2017.

BIRD. Banco Internacional para a Reconstrução e Desenvolvimento.

Envelhecendo em um Brasil mais Velho: implicações do envelhecimento populacional para o crescimento econômico, a redução da pobreza, as finanças públicas e a prestação de serviços, Washington D.C., mar. 2011.

BOHN, H. The behavior of U.S. public debt and deficits. Quarterly Journal of Economics, v. 113, n. 3, p. 949-963, ago. 1998. DOI:

https://doi.org/10.1162/o03355398555793

Are stationarity and cointegration restrictions really necessary for the intertemporal budget constraint? Journal of Monetary Economics, v. 54, n. 7, p. 1837-1847, out. 2007. DOI: https://doi.org/10.1016/j.jmoneco.2006.12.012

BRASIL. Ministério da Fazenda. Secretaria de Previdência Social. Anexo IV.6 do PLDO: Projeções Atuariais para o Regime Geral de Previdência Social - RGPS. Brasília, abril, 2018.

CAETANO, M. Determinantes da Sustentabilidade e do Custo Previdenciário: Aspectos Conceituais e Comparações Internacionais. IPEA, Texto para Discussão no 1226, 2006 a.

. Fundamentos acerca dos riscos associados à previdência social. IPEA,

Texto para Discussão, no 1214, 2006b. aa 
CAMPOS, E. L.; CYSNE, R. P. A time-varying fiscal reaction function for Brazil. Estudos Econômicos, São Paulo, vol. 49 n. 1, p. 5-38, jan/mar. 2019. DOI: http://dx.doi.org/10.1590/o101-41614911ecr

CEPAL. Comisión Económica para América Latina y el Caribe, Observatório Demográfico, Santiago, 2015.

COSTANZI, R. N.; ANSILIERO, G. Impacto fiscal da demografia na previdência social. IPEA, Texto para Discussão, n. 2291, 2017.

COSTANZI, R. N.; AMARAL, A. D.; DIAS, C. R.; ANSILIERO, L.; AFONSO, L, E.; SIDONE, O. J. G. "Reforma da Previdência Social”. In De Negri, J. A.; Araújo, B. C.; Bacelette, R. (org.). Desafios da Nação: Artigos de Apoio, v. 2, p. 678, Brasília, IPEA, 2018.

EVERAERT, G.; JANSEN, S. On the estimation of panel fiscal reaction functions: Heterogeneity or fiscal fatigue? Economic Modelling, v. 70, p. 87-96, 2018. DOI: https://doi.org/10.1016/j.econmod.2017.10.014

GALÍ, J.; PEROTTI, R. Fiscal Policy and Monetary Integration in Europe.

Economic Policy, v.18, n.37: p. 533-572, 2003. DOI: https://doi.org/10.1111/14680327.00115_1

GENTIL, D. L. "A Política Fiscal e a Falsa Crise do Sistema de Seguridade Social no Brasil: Análise Financeira do Período Recente”, in João Sicsú (org.). Arrecadação (De Onde Vem?) e Gastos Públicos (Para Onde Vão?). São Paulo, Boitempo, 2007.

GIAMBIAGI, F. Reforma da Previdência: O Encontro Marcado. Rio de Janeiro: Elsevier, 2007.

GHOSH, A. R.; KIM, J. I.; MENDONZA, E. G.; OSTRY, J. D.; QURESHI, M. S. Fiscal fatigue, fiscal space and debt sustainability in advanced economies, Economic Journal, v. 123, n. 566, p. 4-30, 2013. DOI: https://doi.org/10.1111/ecoj.12010 IBGE. Instituto Brasileiro de Geografia e Estatística. Projeção da população do Brasil e Unidades da Federação por sexo e idade para o período 2010-2060.

Diretoria de Pesquisas, Rio de Janeiro, 2018. de Janeiro, 2016. Tábua completa de mortalidade, (2016, homens e mulheres), Rio JESUS, C. S. A ciclicalidade da política fiscal brasileira revisitada. Reflexões Econômicas, Ilhéus (BA). v. 4. n. 1. p. 77-99. Jul-dez, 2019.

KOURY, F. J. F. Uma função de reação para a análise da sustentabilidade do regime próprio de previdência social dos servidores do estado do Ceará no período 2003-2012. P. 34. Dissertação (Mestrado em Economia), Universidade Federal do Ceará, Fortaleza, 2014. 
MACEDO, M. S.; JESUS, C. S.; DRUMOND, C. E. A (in)sustentabilidade do Regime Próprio da Previdência Social no Estado da Bahia: uma análise empírica para o período 2005-2017. XIV Encontro de Economia Baiana, Salvador, 2018. MATOS, P. R.; MELO, F.; SIMONASSI, A. Análise de Solvência do Regime Geral da Previdência Social no Brasil. Estudos Econômicos, v.43, n. 2, p. 301-333, Abr/Jun 2013. DOI: http://dx.doi.org/10.159o/So101-41612013000200004

MELLO, L. Estimating a fiscal reaction function: the case of debt sustainability in Brazil. Applied Economics, v. 40, p. 271-284, 2007. DOI: https://doi.org/10.108o/00036840500461873

ONU. Organização das Nações Unidas. Department of Economic and Social Affairs, Population Division, World Population Prospects: The 2017 Revision, 2017.

ORAIR, R. O.; BACCIOTTI, R. R. M. Hiato do Produto na Economia Brasileira: estimativas da IFI pela Metodologia de Função de Produção. Brasília: Instituição Fiscal Independente, Estudo Especial, n. 4, 2018.

PAIM, P., MOTA, T., JOSÉ, H. Comissão Parlamentar de Inquérito do Senado Federal destinada a investigar a contabilidade da previdência social, esclarecendo com precisão as receitas e despesas do sistema, bem como todos os desvios de recursos (CPIPREV), Relatório Final, Senado Federal, 2017.

ROCHA, F. Long-run limits on the Brazilian government debt. Revista Brasileira de Economia, v. 51, p. 447-470, 1997. DOI: http://dx.doi.org/10.159o/Soo3471402001000300001

SIMONASSI, A.; ARRAES, R. Função de Resposta Fiscal, Múltiplas Quebras Estruturais e a Sustentabilidade da Dívida Pública no Brasil. Anais do XXXV Encontro Nacional de Economia da ANPEC, Recife-PE, 2007. SOUZA-JÚNIOR, J. R. C. Capacidade Produtiva Ociosa Atual e Projeções para o Produto Potencial 2017-2018. Carta de Conjuntura do IPEA, n. 34, 2017.

STN. Secretaria do Tesouro Nacional. Resultado do Tesouro Nacional. Brasília: Secretaria do Tesouro Nacional, julho, 2018.

TAFNER, P. Desafios e reformas da previdência social brasileira. Revista USP, São Paulo, n. 93, p. 137-153, 2012. DOI: https://doi.org/10.116o6/issn.23169036.voi93p137-156

WORLD BANK. World Bank staff estimates based on age distributions of United Nations Population Division's World Population Prospects: 2017 Revision, 2017. 


\section{Apêndice}

Figura A1: Variáveis utilizadas no modelo de referência (1998T1-2018T1)

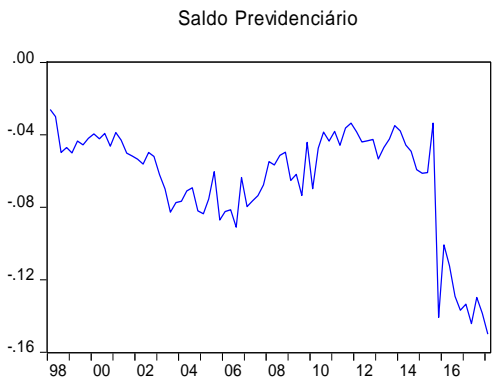

Dívida Previdenciária

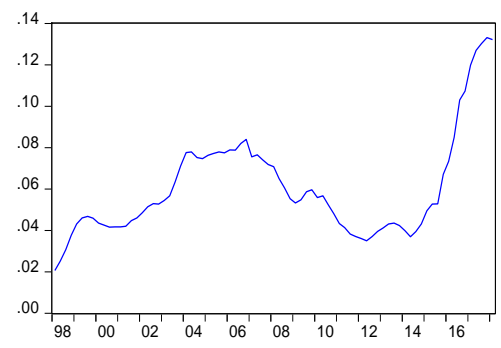

Ciclo da Despesa

Ciclo da Receita
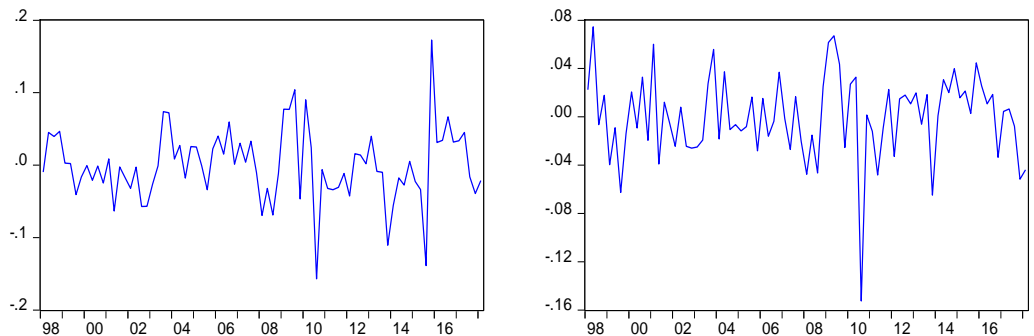

Hiato do Produto

Razão de Dependência de Idosos
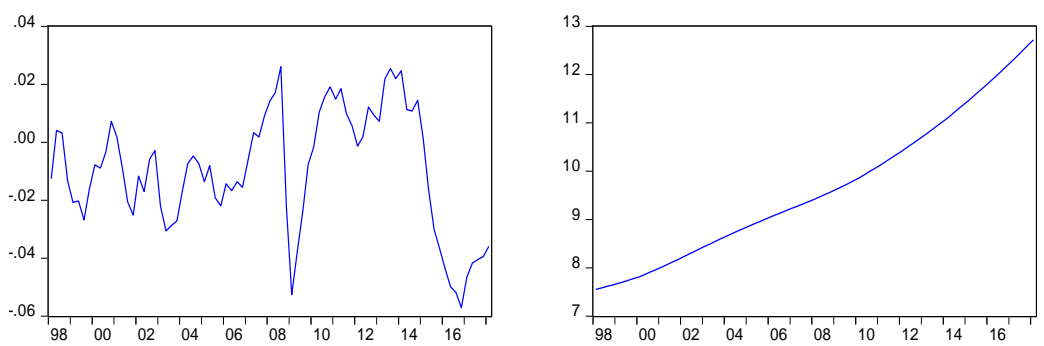

Fonte: Os dados foram coletados no STN, IPEA e Banco Mundial. Cálculos foram feitos pelo autor. 
Figura A2. Coeficientes obtidos por meio de regressões com janelas móveis (MQO)
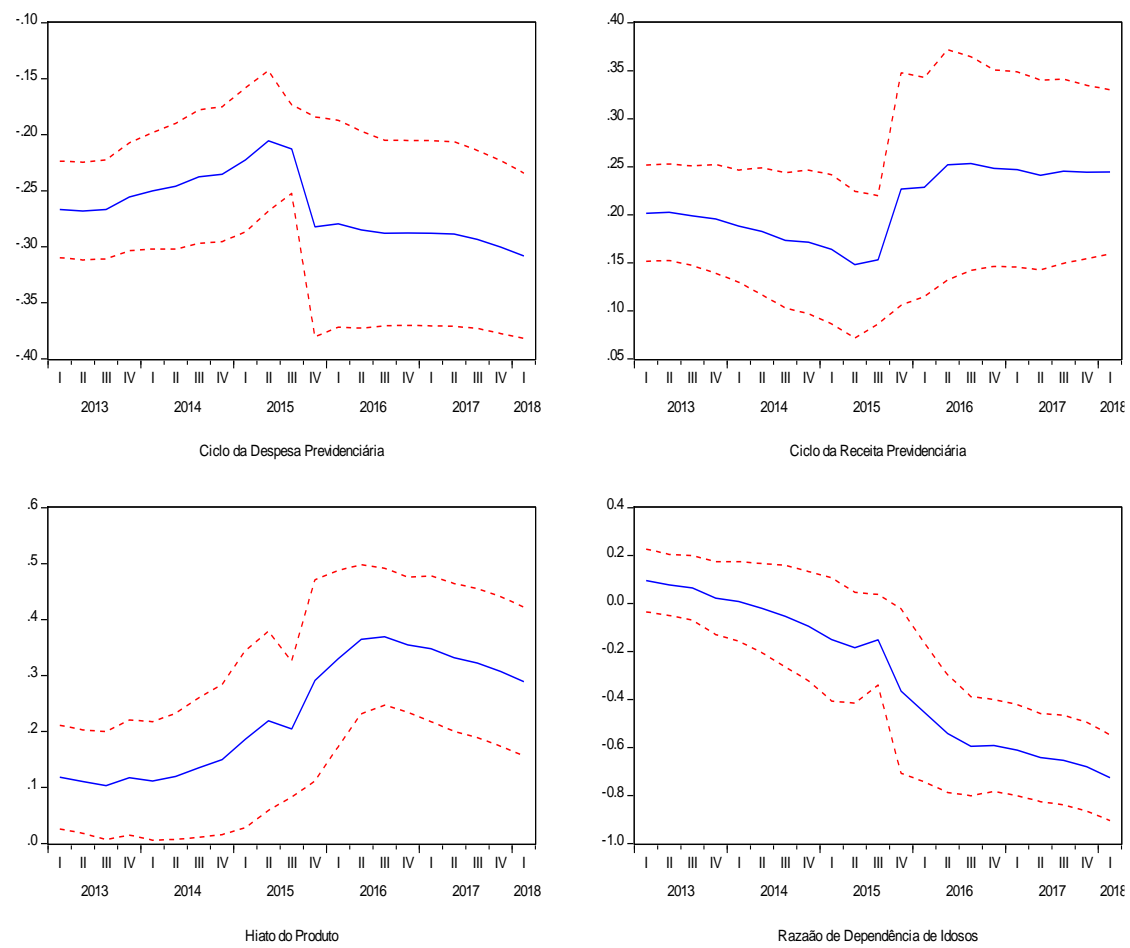

Fonte: cálculo do autor. As janelas são de 60 períodos.

As estimativas referem-se ao modelo de referência. 
Figura A3. Coeficientes obtidos por meio de regressões com janelas móveis (MQO)
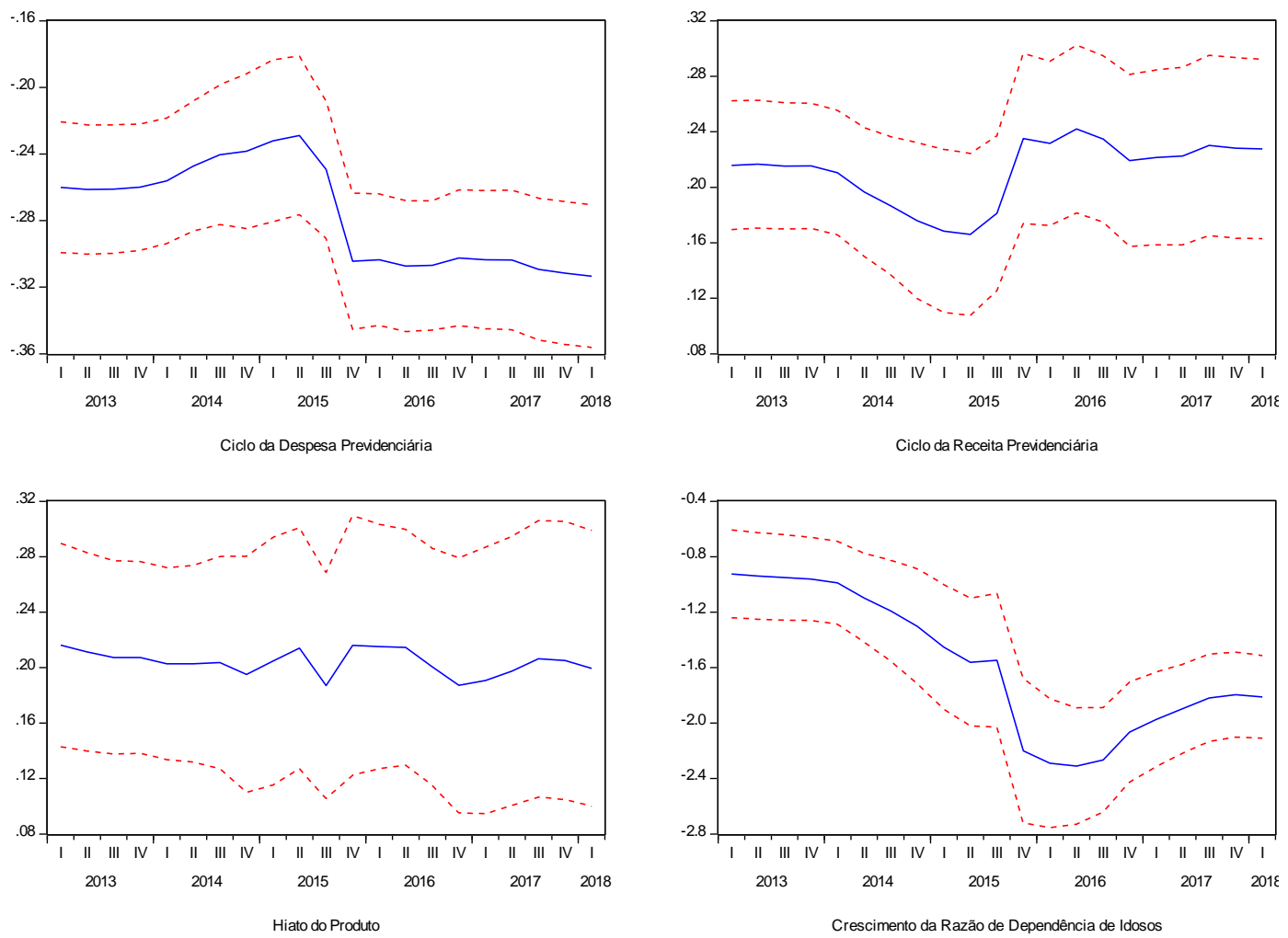

Fonte: cálculo do autor. As janelas são de 6o períodos.

As estimativas referem-se ao modelo alternativo. 
Tabela A1. Variável dependente: saldo previdenciário

\begin{tabular}{|c|c|c|c|}
\hline & MQO & RQ & MQR \\
\hline Constante & $\begin{array}{c}0,03^{*} \\
(0,005)\end{array}$ & $\begin{array}{c}0,03^{*} \\
(0,006)\end{array}$ & $\begin{array}{c}0,03^{*} \\
(0,005)\end{array}$ \\
\hline$e d p_{t-1}$ & $\begin{array}{l}-0,76^{*} \\
(0,054)\end{array}$ & $\begin{array}{l}-0,79^{*} \\
(0,054)\end{array}$ & $\begin{array}{c}-0,80^{*} \\
(0,049)\end{array}$ \\
\hline$\widetilde{d p}_{t}$ & $\begin{array}{l}-0,29^{*} \\
(0,023)\end{array}$ & $\begin{array}{l}-0,29^{*} \\
(0,051)\end{array}$ & $\begin{array}{l}-0,25^{*} \\
(0,021)\end{array}$ \\
\hline$\widetilde{r p}_{t}$ & $\begin{array}{c}0,20^{*} \\
(0,032)\end{array}$ & $\begin{array}{l}0,19^{* *} \\
(0,053)\end{array}$ & $\begin{array}{c}0,23^{*} \\
(0,029)\end{array}$ \\
\hline$y_{t}$ & $\begin{array}{c}0,33^{*} \\
(0,057)\end{array}$ & $\begin{array}{l}0,40^{*} \\
(0,07)\end{array}$ & $\begin{array}{c}0,37^{*} \\
(0,053)\end{array}$ \\
\hline$r d_{t}$ & $\begin{array}{l}-0,46^{*} \\
(0,063)\end{array}$ & $\begin{array}{l}-0,48^{*} \\
(0,063)\end{array}$ & $\begin{array}{l}-0,42^{*} \\
(0,058)\end{array}$ \\
\hline Recessão & $\begin{array}{l}-0,009 \\
(0,002)\end{array}$ & $\begin{array}{c}-0,012 \\
(0,003)\end{array}$ & $\begin{array}{l}-0,009 \\
(0,002)\end{array}$ \\
\hline $\mathrm{R}^{2}\left(\mathrm{R}_{\mathrm{W}}\right)$ ajust. & 0,95 & 0,76 & 0,97 \\
\hline
\end{tabular}

Notas: $\left({ }^{*}\right)$ e $\left({ }^{* *}\right)$ estatisticamente significante a $1 \%$ e $5 \%$.

Em parênteses estão os erro-padrões de cada coeficiente. 